\title{
Effect of two distinct patches of Myriophyllum species on downstream turbulence in a natural river
}

\author{
Łukasz Przyborowski $^{1}$ (D) Anna Maria Łoboda ${ }^{1}$ (D) Robert Józef Bialik ${ }^{2}$ (D)
}

Received: 17 September 2018 / Accepted: 16 April 2019 / Published online: 29 April 2019

(c) The Author(s) 2019

\begin{abstract}
Velocity profiles upstream and downstream of two aquatic plant species that are similar in morphology but differ in patch structures were measured in a natural river. Turbulence statistics were analyzed after thorough data filtering. In the wake of the M. alterniflorum, which was a slender, $0.3 \mathrm{~m}$ wide and $1.2 \mathrm{~m}$ long patch of aspect ratio 1:4, there were distinctive peaks in both, turbulence intensity and turbulent kinetic energy, which indicated increased lateral mixing. In contrast to the $M$. alterniflorum, turbulence statistics in the wake of the M. spicatum, which was the larger, $2 \mathrm{~m}$ wide and $2.4 \mathrm{~m}$ long patch of aspect ratio 1:1.5, indicated increased lateral shear of a greater magnitude. The turbulent kinetic energy was diminished in the closest layer to the bed downstream the both plants, although, in the case of M. alterniflorum, the observed values were similar to those upstream. The occurrence of the mixing layer below the height of M. spicatum was visible in the power spectral density plot. In both cases, ejections in the wake diminished in favor of other coherent structures. The shape and configuration of a patch are decisive factors governing the occurrence of flow instabilities downstream of the patch.
\end{abstract}

Keywords Aquatic plants $\cdot$ Mixing layer $\cdot$ Turbulence $\cdot$ Flow field $\cdot$ Flexible vegetation patches

\section{Introduction}

The role and performance of both aquatic and riparian plants in rivers have been intensively investigated in recent years by in situ measurements (e.g., Biggs et al. 2016; Cameron et al. 2013; Cassan et al. 2015; Naden et al. 2006; Sukhodolova and Sukhodolov 2012; Västilä et al. 2015) and laboratory experiments (e.g., Kubrak et al. 2015; Liu et al. 2017; Siniscalchi and Nikora 2013; Termini and Di Leonardo 2017). The growing interest in the complexity of flow-biota-sediment interactions and their impacts on flow resistance and transport processes and thus, on river management (Aberle

Łukasz Przyborowski

lprzyborowski@igf.edu.pl

Anna Maria Łoboda

aloboda@igf.edu.pl

Robert Józef Bialik

rbialik@ibb.waw.pl

1 Institute of Geophysics, Polish Academy of Sciences, Warsaw, Poland

2 Institute of Biochemistry and Biophysics, Polish Academy of Sciences, Warsaw, Poland and Järvelä 2015; Gurnell et al. 2012; Nepf 2012a; Nikora 2010) stresses the need for further studies to be conducted.

Plants in the form of individual patches that are much smaller than the river width are common in natural conditions (Siniscalchi et al. 2012). Each patch contributes to the flow blockage factor, which depends on the drag coefficient, patch density and diameter (Ortiz et al. 2013). These coefficients have a subtler influence on the detailed flow field due to the multiple scales at which a plant interacts with the flow, creating various effects in the form of boundary and mixing layers (Nikora 2010). The identification of a single phenomenon like stem induced vortices is very difficult due to the intersection of different-scale effects (Aberle and Järvelä 2013). In response to this issue, the superposition of multiple individual concepts that can describe the flow downstream of vegetation was proposed by Nikora et al. (2013).

The vortices occur at different scales; some propagate from individual stems as flows separate from their boundary, while others originate from the Kelvin-Helmholtz instability at the patch boundaries (Nikora 2010). For example, the distinct phenomena observed in the wake of a patch, which has higher drag than the bed, are patch-scale turbulences in the form of vertical and horizontal vortices, which propagate downstream (Aberle and Järvelä 2015). In the case of 
emergent vegetation, horizontal patch-scale vortices are prone to merge after reaching a certain distance, which depends on the patch diameter and density (Nepf 2012a). These phenomena limit the area of decreased velocity where sediment deposition is increased downstream of the plant (e.g., Liu et al. 2017).

In a vegetated channel, the energy cascade is disturbed by the occurrence of coherent structures (e.g., Nezu and Nakagawa 1993). In the flow over a sandy mobile bed without vegetation, a bursting cycle occurs, where sweeps and ejections mostly contribute to turbulence close to the boundary layer (Grass 1971). Ghisalberti and Nepf (2006) and further Chen et al. (2013) revealed that the character of secondary currents changes from ejections to sweeps within the canopy. Within a patch of flexible vegetation, sweeps bend the stems and ejections are responsible for lifting them (Sukhodolova and Sukhodolov 2012). Sweeps within the canopy are dominant over the ejections, as revealed in studies by, for example, Chen et al. (2013) and Termini and Di Leonardo (2017). In addition, within a plant patch, naturally flexible vegetation tends to undergo dynamic reconfiguration correlated with ambient flow. This behavior can suppress increased turbulence intensities, shear stresses and flow separation, which are common for rigid obstacles in water (Ghisalberti and Nepf 2006; Siniscalchi and Nikora 2013).

Theories describing flow disturbances in the presence of flexible, naturally growing aquatic vegetation are still highly limited due to the complexity of physical laws governing turbulent flow and the heterogeneity of natural conditions in each studied case. Following recent trends in vegetated flow investigations (Sukhodolov 2015), an experiment involving the deployment of an acoustic Doppler velocimeter around two common aquatic macrophytes in a natural river was conducted to measure 3D velocity field. A discussion of raw data reliability using a Vectrino Profiler was included in a previous paper by the authors (Przyborowski et al. 2018b). The two species investigated, namely, Myriophyllum alterniflorum L. and Myriophyllum spicatum L., are characterized by similar morphologies (Kłosowski and Kłosowski 2007; Wilson and Ricciardi 2009); therefore, in response to flow stresses, individual stems of comparable diameter and with the same internal structure should respond in a replicable manner. This similarity raises the question of how the dimensions and configuration of the patch alter flow properties downstream. As Nikora et al. (2008) showed, patch width $\left(W_{\mathrm{c}}\right)$ to the flow width $(W)$ ratio is one of the meaningful plant roughness parameters. In this study, both patches had uniformly covered a small part of the bed; however, M. spicatum had much higher value of $W_{\mathrm{c}} / W$, and therefore, it was expected to produce similar flow instabilities to those of submerged meadows as described by Nepf (2012a), for example. The obtained results showed differences in the velocity profiles between plant patches. This paper shows the development of these results; after thorough data filtering, the statistical analysis of turbulence was conducted to determine the flow instabilities caused by the two distinct patches.

\section{Study site}

The present experiments were conducted at two sites in the Świder River in Poland, which is a sandy bed, lowland river with a width of approximately $20 \mathrm{~m}$. During the first experiment on July 16, 2016, the discharge was $2.46 \mathrm{~m}^{3} \mathrm{~s}^{-1}$. A slender, $0.3 \mathrm{~m}$ wide and $1.2 \mathrm{~m}$ long patch (aspect ratio 1:4) of M. alterniflorum was found approximately $2 \mathrm{~m}$ from the right bank in $0.35 \mathrm{~m}$ deep water and two pairs of velocity profiles were measured (Fig. 1a, b). During the second experiment on September 22, 2016, the discharge was lower, i.e., $1 \mathrm{~m}^{3} \mathrm{~s}^{-1}$, and the water depth was approximately $0.25 \mathrm{~m}$. A patch of $M$. spicatum, which covered an approximately $2 \mathrm{~m}$ wide and $1.5-2.4 \mathrm{~m}$ long area (the aspect ratio was approximately $1: 1.5$ due to the irregular shape of the patch; also, the velocity profiles were placed not in the centerline of the patch but closer to its edge, as shown in Fig. 1d) was found $1 \mathrm{~m}$ from the left bank (Fig. 1d, e). In both experiments, the average difference in water depth between the upstream and downstream profiles was approximately $3 \mathrm{~cm}$. Ripples were observed on the sandy bed. However, no bed elevation changes were observed during any $3 \mathrm{~min}$ long recording. In the vicinity of the experimental sites, there were no other obstacles on the riverbed; therefore, the upstream profiles represent undisturbed ambient open-channel flow.

Although the number of stems per unit bed area was not measured, the second patch was visually denser (Fig. 1b, e). Both investigated plant species belong to group of fully submerged types of vegetation. The species are characterized by similar morphologies of stems and leaves (Fig. 1c, f). The only difference was that the individual stems of $M$. spicatum were approximately $0.20 \mathrm{~m}$ shorter than those of $M$. alterniflorum. The diameter of the stem, which has a wheel-like internal structure (Łoboda et al. 2018b), was approximately $2 \mathrm{~mm}$ (Fig. 1g, h). Thin, 10-20 mm long whorled leaves grew in sets of three per node along the stem (Kłosowski and Kłosowski 2007). Differences in biomechanical properties between the two investigated species, which might influence the obtained turbulence statistics, were not evaluated due to the assumption of similar average flexural rigidities for plants with similar morphologies (Fig. 1c, f), stem diameters and cross-sections (Fig. 1g, h) (experiments were conducted after the rapid growth season of the plants; Łoboda et al. 2018a; Tymiński and Kałuża 2012). 

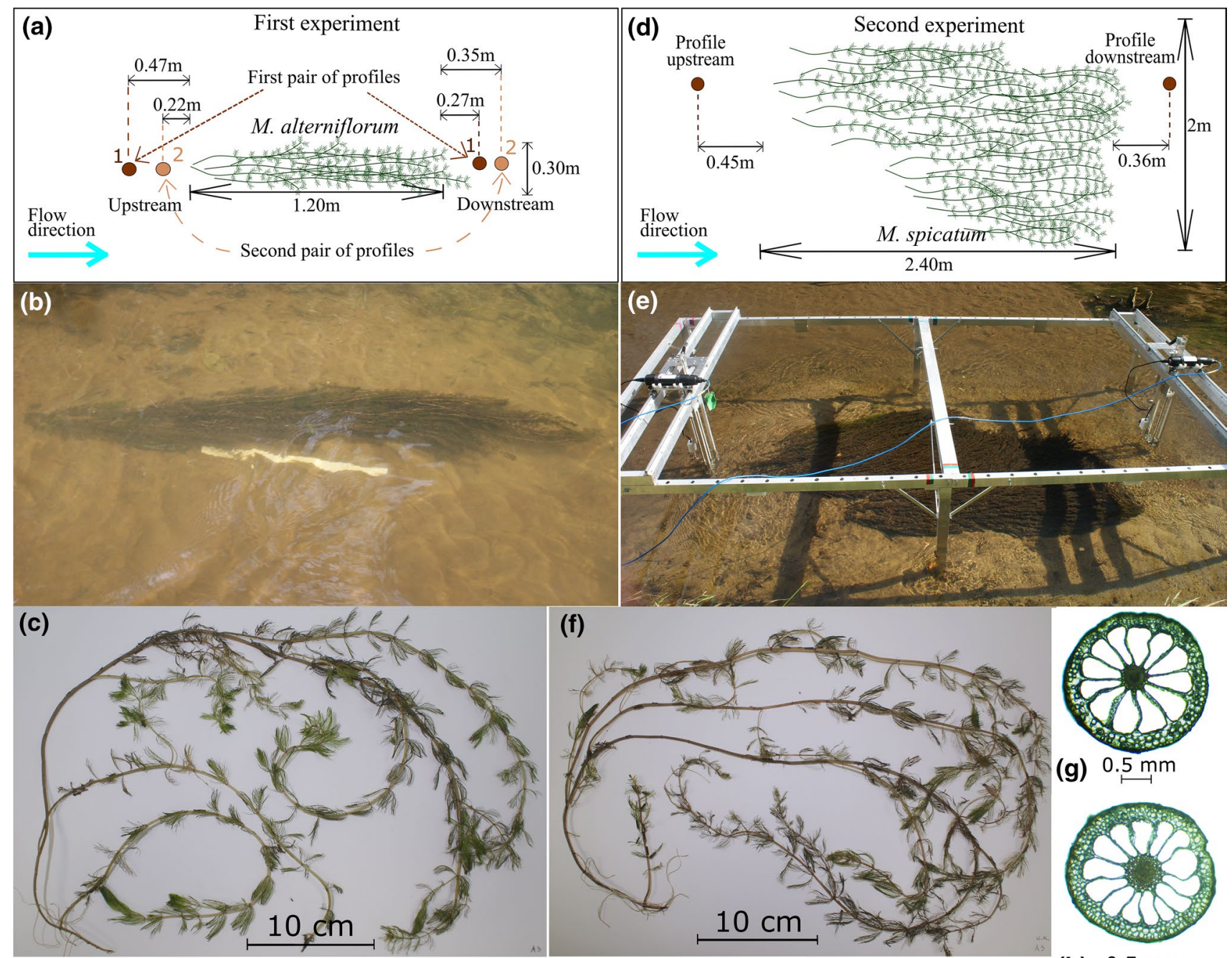

(h) $0.5 \mathrm{~mm}$

Fig. 1 Schematics of the two patches with locations of measured profiles (a, d); photographs taken at the experimental sites (b a patch of $M$. alterniflorum; e a patch of $M$. spicatum with a platform used to hold velocimeters); photographs of examples of individual stems and

\section{Materials and methods}

Water velocity measurements were performed using an acoustic Doppler velocimeter, the Vectrino Profiler (VP) (revision 2779/1.32, Nortek AS, Rud, Norway). During the measurements, the following VP setup was used: minimum ping algorithm; $50 \mathrm{~Hz}$ recording frequency; high power level; and a velocity range $0.2 \mathrm{~m} \mathrm{~s}^{-1}$ higher than the first recorded mean value. In the first experiment, the first pair of profiles was obtained $0.27 \mathrm{~m}$ downstream and $0.47 \mathrm{~m}$ upstream of the plant, and the second pair of profiles was obtained $0.35 \mathrm{~m}$ downstream and $0.22 \mathrm{~m}$ upstream of the plant (Fig. 1a). In the second experiment, one pair of profiles was obtained at points $0.36 \mathrm{~m}$ downstream and $0.45 \mathrm{~m}$ upstream (Fig. 1d), measured simultaneously with two plant stem cross-sections (c, $\mathbf{g}$ M. alterniflorum; f, $\mathbf{h}$ M. spicatum). Please note the white strip in the photograph $\mathbf{b}$ is $0.5 \mathrm{~m}$ long ruler, and the photograph, e does not show actual placement of measurement profiles

VP units. It is also worth noting that the distance between upstream and downstream profiles was two times larger for the second patch than for the first patch due to the length of the patches (Fig. 1a, d). Each profile was created from a series of individual 3 min recordings taken at different water heights. Results from the velocity measurements were depicted using normalized height, i.e., a $Z / H$ scale, where $Z$ represents the height of the measurement point above the bed and $H$ represents the local water depth. The average height of the main body of the plant was approximately $Z / H=0.5$ for $M$. alterniflorum and approximately $Z / H=0.4$ for M. spicatum.

Before using the recorded velocities to calculate turbulence characteristics, a filtering procedure was applied to the recorded velocities to remove low-quality or noise-related 
artifacts of the VP (Brand et al. 2016; Koca et al. 2017; Thomas et al. 2017). The procedure was as follows: (1) the cell with the best signal-to-noise ratio (SNR) and within a "sweet spot," i.e., the distance from the VP transducers where the signal beams were best correlated, was chosen from each data recording; (2) the record from the chosen cell was cleared of fragments with an SNR below $15 \mathrm{~dB}$ or correlation below $70 \%$ and replaced with interpolating neighboring values; (3) spikes were removed using a phase-space thresholding filter (Goring and Nikora 2002, with modifications by Wahl 2003 and Parsheh et al. 2010).

The signal-to-noise ratio during the velocity measurements near M. alterniflorum was generally above $20 \mathrm{~dB}$ in points in the "sweet spot," and the SNR was below this level for M. spicatum. To maintain the best accuracy, for a few points across profiles, bins outside the "sweet spot" had to be chosen; therefore, the results, even after filtering procedures, must be interpreted with caution. Due to the low SNR values of the points closest to the bottom, some of them were removed from results. The lowest measured point downstream of $M$. alterniflorum, showed in the results, was $7 \mathrm{~cm}$ above the bed in the first profile; $4 \mathrm{~cm}$ above the bed in the second downstream profile, whereas the lowest point downstream of $M$. spicatum was $2 \mathrm{~cm}$ above the bed.

Turbulence characteristics were calculated using recorded and filtered velocity fluctuations in longitudinal $\left(u^{\prime}\right)$, transverse $\left(v^{\prime}\right)$ and first vertical $\left(w^{\prime}\right)$ directions. The Reynolds stresses were formulated as follows:

$\overline{u^{\prime} v^{\prime}}, \overline{v^{\prime} w^{\prime}}$ and $\overline{u^{\prime} w^{\prime}}$,

the normalized turbulence intensities are:

$\mathrm{TI}_{U}=\frac{\sqrt{\overline{u^{\prime 2}}}}{\bar{U}}, \quad \mathrm{TI}_{V}=\frac{\sqrt{\overline{v^{\prime 2}}}}{\bar{U}}, \quad$ and $\quad \mathrm{TI}_{W}=\frac{\sqrt{\overline{w^{\prime 2}}}}{\bar{U}}$,

where $\bar{U}$ denotes the time-averaged longitudinal velocity; and the turbulent kinetic energy is:

$\mathrm{TKE}=\frac{1}{2}\left(\overline{\left(u^{\prime}\right)^{2}}+\overline{\left(v^{\prime}\right)^{2}}+\overline{\left(w^{\prime}\right)^{2}}\right)$.

In addition, these characteristics were made noise-free due to the availability of redundant information for two vertical velocities recorded by the VP (Hurther and Lemmin 2001; Voulgaris and Trowbridge 1998) by subtracting the calculated noise variance in each direction from the corresponding velocity variance. To show the power spectral densities, a script implemented in MATLAB was used, i.e., the Welch (1967) method. A Hamming window function and discrete Fourier transform points equal to 512 with a $50 \%$ overlap were chosen (Koca et al. 2017).

Quadrant analysis was performed using a bursting cycle detection method (Franca et al. 2014). Shear events were detected using the following thresholds: for outward interactions,

$Q_{\mathrm{out}}=\left\{u^{\prime}, w^{\prime} \in R: u^{\prime}>0 \bigwedge w^{\prime}>\frac{\sigma_{\mathrm{h}}}{u^{\prime}} \bigwedge u^{\prime}<\sigma^{+}\right\} ;$

for ejections,

$Q_{\mathrm{ej}}=\left\{u^{\prime}, w^{\prime} \in R: u^{\prime}<0 \bigwedge\left\{w^{\prime}>\frac{\sigma_{\mathrm{h}}}{\left|u^{\prime}\right|} \bigvee u^{\prime}<\sigma^{-}\right\}\right\}$

for inward interactions,

$Q_{\mathrm{inw}}=\left\{u^{\prime}, w^{\prime} \in R: u^{\prime}<0 \bigwedge w^{\prime}<0 \bigwedge\left|w^{\prime}\right|>\frac{\sigma_{\mathrm{h}}}{\left|u^{\prime}\right|} \bigwedge u^{\prime}>\sigma^{-}\right\} ;$

and for sweeps,

$Q_{\mathrm{sw}}=\left\{u^{\prime}, w^{\prime} \in R: u^{\prime}>0 \bigwedge\left\{\left\{w^{\prime}<0 \bigwedge\left|w^{\prime}\right|>\frac{\sigma_{\mathrm{h}}}{u^{\prime}}\right\} \bigvee u^{\prime}>\sigma^{+}\right\}\right\} ;$

where the threshold $\sigma_{\mathrm{h}}$ was obtained by the following equation

$\sigma_{\mathrm{h}}=H \times U_{\mathrm{rms}} \times W_{\mathrm{rms}}$

and the thresholds $\sigma^{+}$and $\sigma^{-}$, by:

$\sigma^{ \pm}= \pm 2.5 \times U_{\text {rms }}$.

$H$ represents the hole size, which was 1.8 as this value is commonly used for open-channel flows (e.g., Liu et al. 2016), although, in order to consider weak events, this value could be lower, i.e., 1.2 as suggested by Luchik and Tiederman (1987) or even 0.2 as used by Bialik (2013). However, Poggi et al. (2004) and Chen et al. (2013) used a value of 3 in their experiments with vegetation in laboratory conditions for a classical detection method. $U_{\mathrm{rms}}$ and $W_{\mathrm{rms}}$ were equal to the root mean squares of the longitudinal and vertical velocities, respectively.

\section{Results}

The mean longitudinal velocities were decreased by $43 \%$ to $50 \%$ in each of the downstream profiles in comparison with upstream profiles (Fig. 2). The mean transverse and vertical velocities did not change significantly around $M$. alterniflorum, although in the case of M. spicatum, the mean transverse velocities had positive values, from 0.100 to $0.180 \mathrm{~m} \mathrm{~s}^{-1}$ downstream through the whole height of the plant patch, while upstream they oscillated from -0.002 to $0.009 \mathrm{~m} \mathrm{~s}^{-1}$ (Fig. 2).

The measured normalized turbulence intensities were, on average, $77 \%$ to $168 \%$ higher downstream of $M$. alterniflorum and $25 \%$ to $198 \%$ higher downstream of M. spicatum, than upstream of them (Fig. 3). Below the height of the M. alterniflorum patch, the highest $T I$ values were detected in the downstream profile 2 which indicated that 

transverse $\bar{V}$ and vertical $\bar{W}$ velocities of the first and second pair of profiles downstream and upstream of $M$. alterniflorum and of one pair of profiles in the experiment with $M$. spicatum. Note that the dotted lines indicate the average height of the plant
Fig. 2 Mean longitudinal $\bar{U}$,
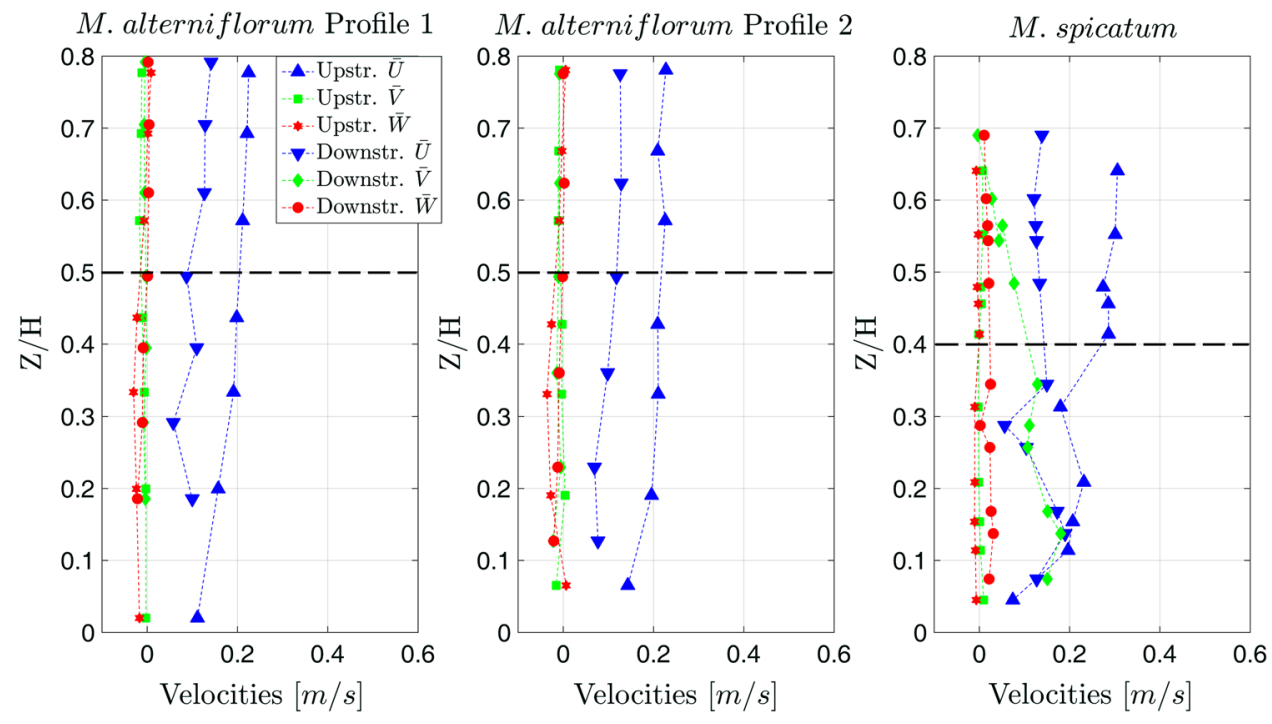

Fig. 3 Normalized turbulence intensities of the first and second pair of profiles downstream and upstream of M. alterniflorum and of one pair of profiles in the experiment with $M$. spicatum. Note that the dotted lines indicate the average height of the plant

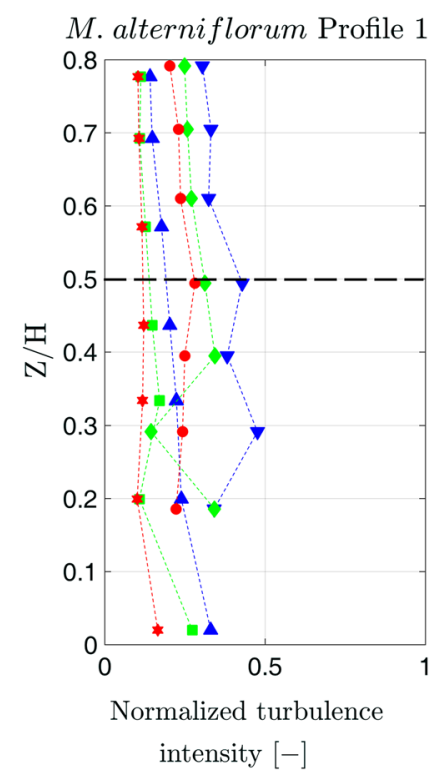

mixing was developing in the farther profile. Downstream of the $M$. spicatum there was a distinctive peak in points at $Z / H=0.29$ and $Z / H=0.26$, where the $T I_{\mathrm{U}}$ and $T I_{\mathrm{V}}$ were four to nine times higher than closest corresponding points in height upstream, denoting increased mixing (Fig. 3), as was expected for the larger patch. However, the $T I_{\mathrm{W}}$ values in this region were noticeably low.

The turbulent kinetic energy (TKE) profiles downstream of the investigated plants showed trends opposite to those of the turbulence intensities, i.e., the TKE was higher above the main body of the plant than below that height (Fig. 4). At $Z / H=0.5$, i.e., the height of the $M$. alterniflorum canopy, the TKE was $0.0013 \mathrm{~m}^{2} \mathrm{~s}^{-2}$, equal in both the upstream and downstream profile 1 ; at $Z / H=0.3$ the TKE was two times lower; farther in the downstream profile 2 and at $Z / H=0.5$, the TKE value was higher than upstream (Fig. 4), while at

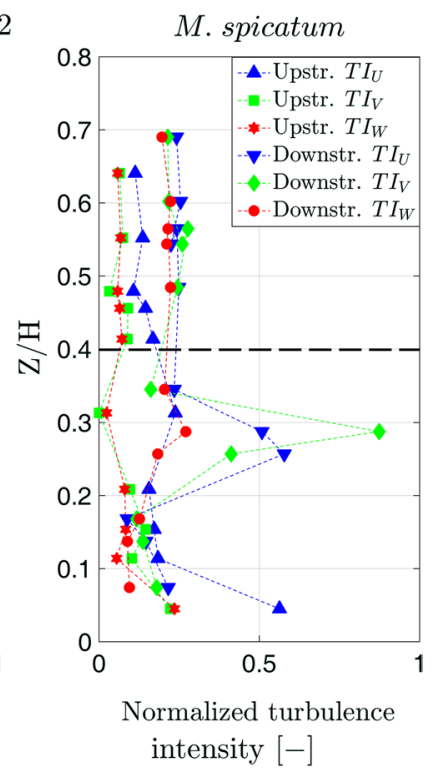

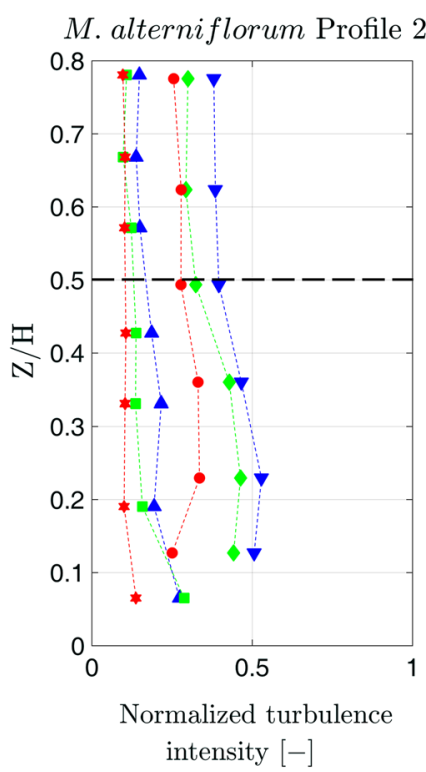

$Z / H=0.2$ it was similar to the upstream profile. Downstream of M. spicatum, the TKE profile retained a distinctive peak in the same spot as the turbulence intensities, i.e., below the maximal height of the canopy, which was $0.0029 \mathrm{~m}^{2} \mathrm{~s}^{-2}$, and the lowest value of $0.0004 \mathrm{~m}^{2} \mathrm{~s}^{-2}$ was registered above that height (Fig. 4).

The absolute tangential Reynolds stresses showed fewer changes between the upstream and downstream measurements than did the turbulence characteristics as described above. For M. alterniflorum, the $\left|\overline{u^{\prime} v^{\prime}}\right|$ and $\left|\overline{v^{\prime} w^{\prime}}\right|$ components were highest at $Z / H=0.4$, measuring $0.35 \times 10^{-3} \mathrm{~m}^{2} \mathrm{~s}^{-2}$ and $0.54 \times 10^{-3} \mathrm{~m}^{2} \mathrm{~s}^{-2}$, respectively (Fig. 5). Farther downstream, these peaks were lower, i.e., at $Z / H=0.2$ (Fig. 5). Profiles of $\left|\overline{u^{\prime} w^{\prime}}\right|$ showed elevated values of approximately $0.2 \times 10^{-3} \mathrm{~m}^{2} \mathrm{~s}^{-2}$ at points closest to the bed. Downstream 
Fig. 4 Turbulent kinetic energy of the first and second pair of profiles downstream and upstream of $M$. alterniflorum and of one pair of profiles in the experiment with M. spicatum. Note that the dotted lines indicate the average height of the plant
Fig. 5 Absolute tangential Reynolds stresses of the first and second pair of profiles in the experiment with $M$. alterniflorum and of one pair of profiles in the second experiment with $M$. spicatum. Note that the dotted line indicates the average height of the plant

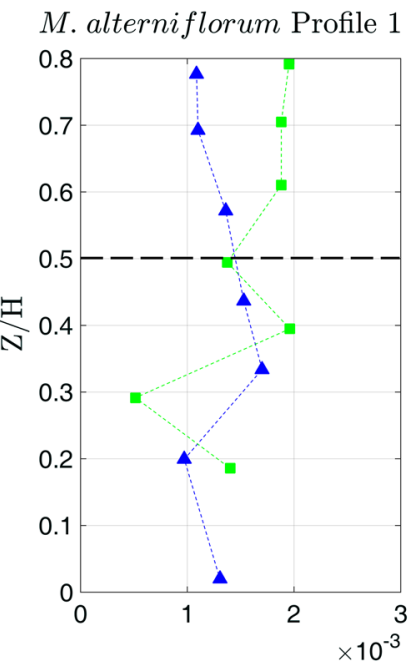

Turbulent Kinetic Energy $\left[m^{2} s^{-2}\right]$

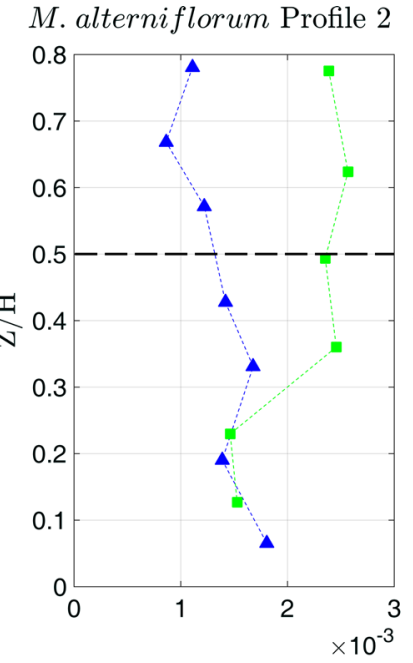

Turbulent Kinetic Energy $\left[\mathrm{m}^{2} \mathrm{~s}^{-2}\right]$

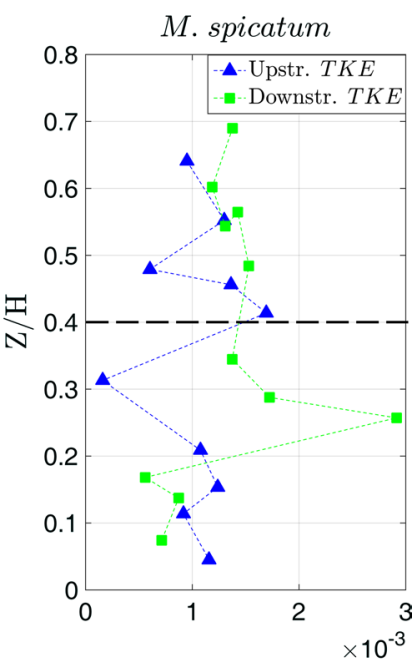

Turbulent Kinetic Energy $\left[m^{2} s^{-2}\right]$

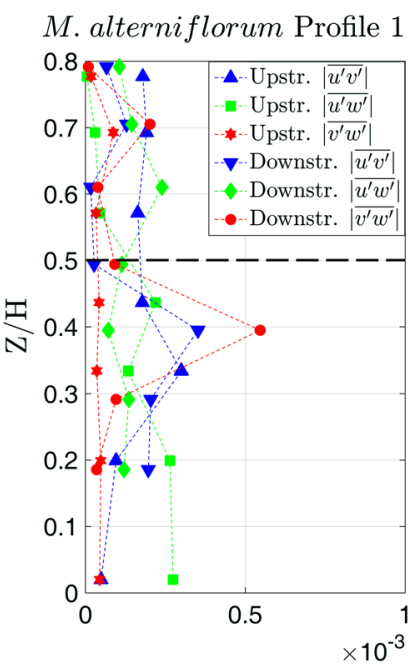

Reynolds Stresses $\left[\mathrm{m}^{2} \mathrm{~s}^{-2}\right]$

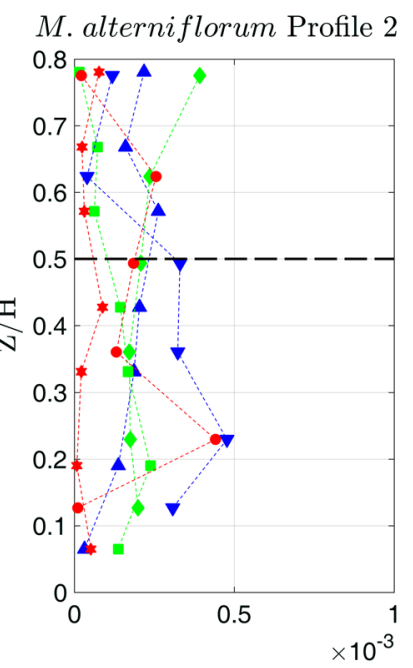

Reynolds Stresses $\left[m^{2} s^{-2}\right]$

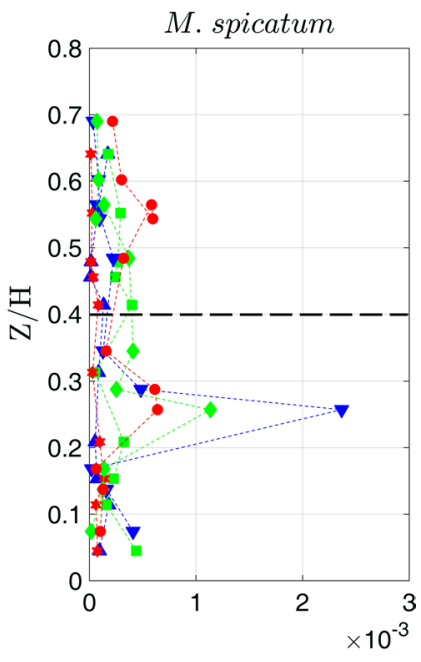

Reynolds Stresses $\left[m^{2} s^{-2}\right]$ of $M$. spicatum, the highest peaks occurred slightly below the canopy height, where the $\left|\overline{u^{\prime} v^{\prime}}\right|,\left|\overline{u^{\prime} w^{\prime}}\right|$ and $\left|\overline{v^{\prime} w^{\prime}}\right|$ components were $0.24,0.12$ and $0.06 \times 10^{-3} \mathrm{~m}^{2} \mathrm{~s}^{-2}$, respectively, indicating a layer of increased shear (Fig. 5).

The power spectral density (PSD) plots of the longitudinal velocity fluctuations (Fig. 6) showed inconsistencies between the three measured pairs of profiles, i.e., in the first pair, the PSD was higher in the upstream profile; in the second pair, it was the same as that downstream; and, for M. spicatum, the downstream profile had a higher spectral density. The magnitude of downstream fluctuations throughout the whole spectrum also varied in each case, i.e., at the $2 \mathrm{~Hz}$ frequency in the first profile, it was below $10^{-4}\left(\mathrm{~m}^{2} \mathrm{~s}^{-2}\right) \mathrm{Hz}^{-1}$; farther downstream, it increased slightly; and it was highest for the second species. Notably, the slope of the PSD in the second pair of profiles exhibited the best fit to the $-5 / 3$ scaling range (Kolmogorov 1991), which is common for free flow in open channels (Nezu and Nakagawa 1993).

Quadrant analysis showed frequent major events in the second and fourth quadrants in all upstream profiles (Fig. 7). At the two profiles downstream of $M$. alterniflorum, shear stress production was transferred to outward and inward interactions, but sweeps and ejections were still present. For $M$. spicatum, the quadrant plot made from a point downstream was biased because points near the bottom generally had poor quality (this was discussed more broadly in Przyborowski et al. 2018b), and 32\% of the velocity values were replaced during the filtering procedure. Therefore, some information from the recording was lost, especially for inward interactions. However, sweeps tended to 

longitudinal velocity fluctuations in the chosen points from the first and second pair of profiles in the experiment with $M$. alterniflorum, and of one pair of profiles in the second experiment with $M$. spicatum
Fig. 6 Power spectrum of the
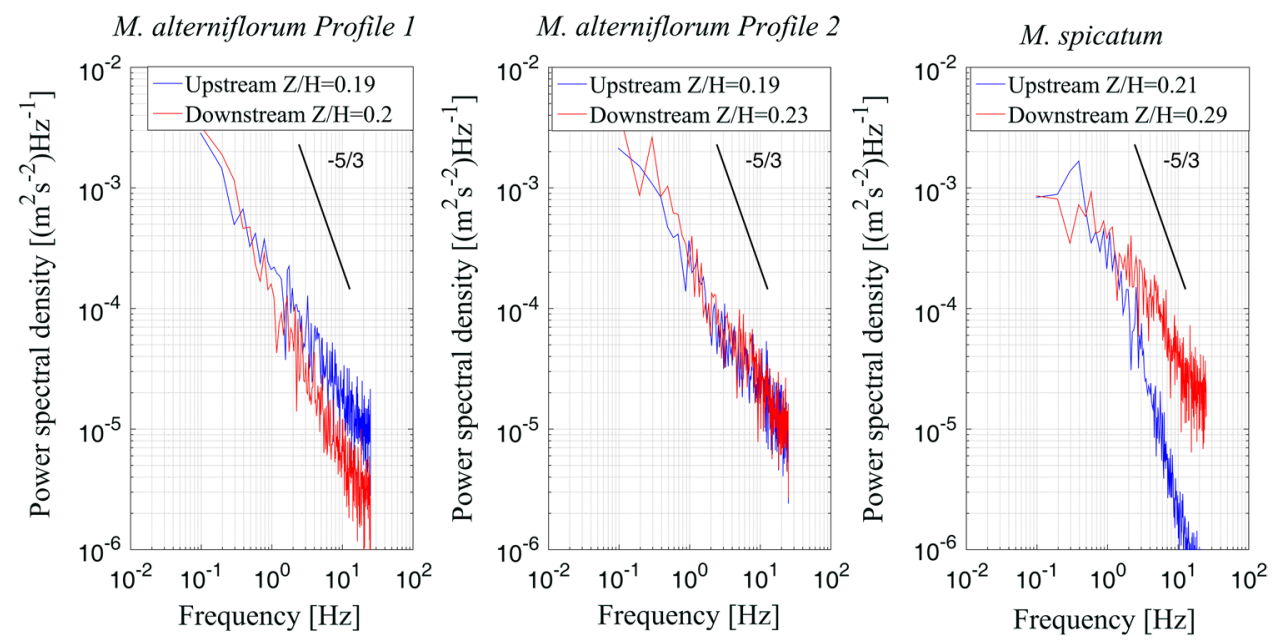

Fig. 7 Quadrant analysis using the bursting cycle detection method at points of specified height. Colors represent points that were above the threshold in each quadrant: green indicates outward interactions; red indicates ejections; blue indicates inward interactions; and purple indicates sweeps

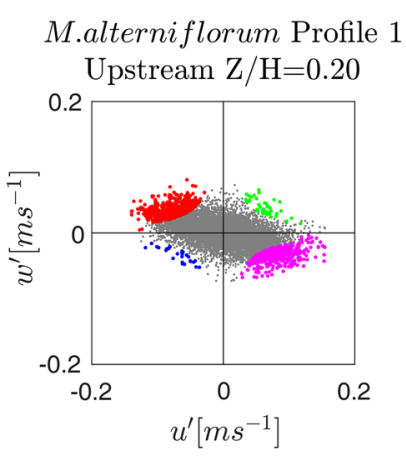

M.alterniflorum Profile 1

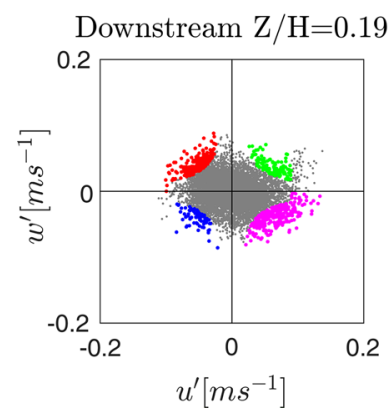

M.alterniflorum Profile 2 Upstream Z/H=0.19

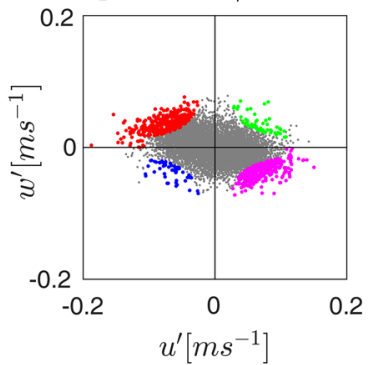

M.alterniflorum Profile 2

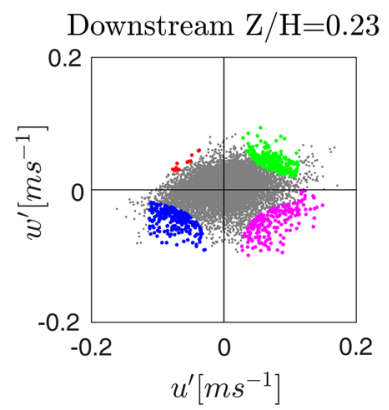

M.spicatum Upstream Z/H=0.21

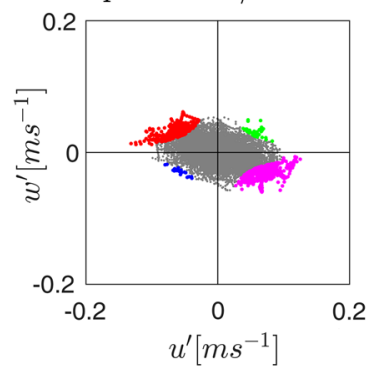

M.spicatum

Downstream Z/H=0.29

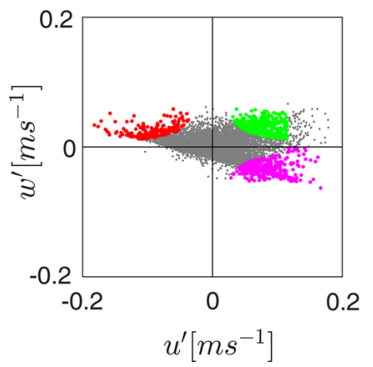

dominate ejections, as in the two profiles downstream of M. alterniflorum.

\section{Discussion}

The coverage percentage of plants as well as their location in the river cross-section influence on channel blockage (Green 2005; O'Hare 2015) and sediment deposition (Västilä and Järvelä 2018). Przyborowski et al. (2018a) showed that patches of Potamogeton pectinatus L. varied due to bed conditions and also, that an individual plant patch had a very limited impact on the flow. The present study shows that single patches of two similar species may have varying

effects on the local flow field, given the major difference in the aspect ratio between these patches, which is consistent with the Nikora et al. (2008) research about the physical vegetation parameters as roughness descriptors. The obtained results of velocities and turbulence intensities downstream of M. alterniflorum (Figs. 2, 3) were in line with those of Hu et al. (2018). In particular, the water velocity in the plant wake was diminished roughly by half, which showed that the patch did not completely block the flow (Fig. 2). Downstream of M. spicatum, of which diameter was at least three times larger and the stems visually covered the whole area densely, the results showed strongly increased, in comparison with $M$. alterniflorum, lateral shear below its maximal height. Another significant difference between the results 
was decreased turbulent kinetic energy observed close to the bed; at the same distance downstream, the decrease in turbulent kinetic energy was better pronounced in the case of the M. spicatum patch (Fig. 4). On the other hand, quadrant analysis showed the same trends in occurrence of the secondary currents downstream the both patches.

\section{Effect of patch geometry on downstream turbulence}

The turbulent kinetic energy (TKE) was elevated in majority of points downstream of M. alterniflorum (Fig. 4). However, in the downstream profile 1 at $Z / H=0.3$, i.e., below the maximum height of the canopy TKE was reduced, where Hu et al. (2018) showed that TKE should be increased in this layer as a sign of elevated shear stresses. In the case of M. spicatum, at the maximum canopy height, TKE was similar to the profile upstream like in the case of the first patch, profile 1 (Fig. 4). For both plants, the TKE inside the wake, i.e., below $Z / H=0.2$, was reduced, in comparison with the values above (Fig. 4), similarly to the experiments of Hu et al. (2018). The differences in the magnitude of TKE at plant height might be caused by the vertical distribution of patch density, where the majority of the stems did not reach the maximum height of the canopy (Fig. 8). Thus, these results were similar to those observed by Sukhodolov and Sukhodolova (2012), where the TKE profile bias, which indicated cumulative effect of mixing and boundary layers, grew with the density of the vegetation.

The position of the measurement profile close to the $M$. spicatum lateral edge had impact on observed turbulence intensities and tangential Reynolds stresses, as it is closer to the plant flow lateral boundary. The highest observed peak at $Z / H=0.25$ in both, longitudinal and transverse turbulence intensities, which peak also appeared in $\left|\overline{u^{\prime} v^{\prime}}\right|$ stress, indi-

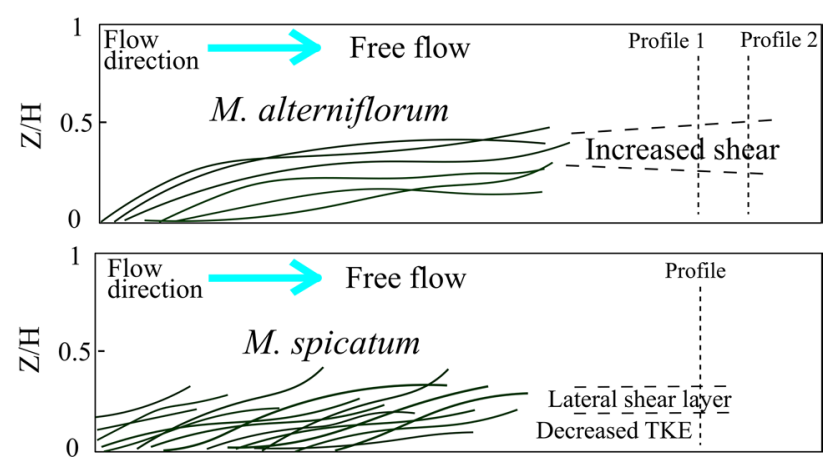

Fig. 8 Schematics of observed flow layers: downstream of the $M$. alterniflorum patch, where a slightly increased turbulent kinetic energy indicated elevated mixing; downstream of the M. spicatum patch, where increased turbulence in transverse direction was observed below the height of the canopy, and decreased TKE were observed closer to the bottom cated the presence of a lateral shear layer (Rominger and Nepf 2011). In comparison with $M$ spicatum, downstream of M. alterniflorum patch, $\left|\overline{u^{\prime} v^{\prime}}\right|$ and $\left|\overline{v^{\prime} w^{\prime}}\right|$ stresses showed about five times smaller lateral transport of momentum at $Z / H=0.4$ in the first downstream profile, which corresponded to the upper part of the plant and in a lower point, i.e., $Z / H=0.25$, in the second profile (Fig. 5). That difference between produced shear was the direct result of the distinct spatial dimensions of the patches (Ortiz et al. 2013).

Similar results as those presented in the paper, showing increased Reynolds stresses, were obtained by Biggs et al. (2016) in an experiment with a Ranunculus penicillatus patch; however, the $\left|\overline{u^{\prime} w^{\prime}}\right|$ shear stress was also elevated, in contrast to the present study, which may be due to differences in bed structure, i.e., sand versus gravel/cobbles. The comparison of the observed $\left|\overline{u^{\prime} w^{\prime}}\right|$ stress and corresponding to it turbulence intensities do not support the presence of vertical Kelvin-Helmholtz vortices in either of patches, phenomenon which was described, e.g., by Nepf (2012b). The cause of such result may be wavy motions of plant stems, which is in line with results obtained by Ghisalberti and Nepf (2006), who observed that an increase in the variability of vegetation height resulted in decreased shear stress.

The PSDs of both the longitudinal and vertical velocities in a wake should have distinct peaks at lower frequencies, marking the passage of vortices. In the case of the occurrence of a mixing layer, the spectral density should be higher than that in the free flow (Ghisalberti and Nepf 2006; Sukhodolov and Sukhodolova 2012). Such phenomenon occurred in the case of the $M$. spicatum patch, where a distinctive peak in the turbulence intensity (Fig. 3) translated into the higher energy visible in the PSD from that point. In this experiment, the PSD showed peaks similar in magnitude at lower frequencies; however, at higher frequencies, energy dissipated faster in the downstream profile closer to M. alterniflorum, than in the profile farther away (Fig. 6), where the turbulence intensity was elevated (Fig. 3). This indicated that the energy transport in profile 2 downstream was the same as in the free flow, but with increased mixing.

\section{The main differences between complex natural vegetation and simplified rigid laboratory studies}

The present study showed that differences in turbulent statistics describing phenomena such as a mixing layer were not as clearly distinguishable as in flumes with rigid rods (Chen et al. 2013). However, such a comparison of artificial rigid patches to real flexible vegetation has limitations. Ortiz et al. (2013) showed that flexible patches have much lower impact on the flow than its rigid counterpart. What is more, there are major differences in biomechanical properties between rigid and flexible materials, which influence plant responses 
to flow and thus, flow resistance (Łoboda et al. 2018a). For instance, lower flexural rigidity indicates that the plant bends and moves with the flow and thus, decreases its frontal area (Nikora 2010). Additionally, for real patches of vegetation, the majority of species such as Myriophyllum have stems reaching far beyond the area of the roots, floating above the bed, as was depicted in Siniscalchi and Nikora (2013). Therefore, it is difficult to compare the number of stems per unit bed area. Moreover, the ratio of water depth $(H)$ to patch height $(h)$ was considered shallow in the present case $(H / h \sim 2)$, although there was no solid upper boundary of the patches, as observed in laboratory studies (e.g., Chen et al. 2013), thus expected velocity gradient downstream the patch was not pronounced.

In the present study, quadrant analysis at points in the wake of M. alterniflorum revealed that ejections were diminished in favor of inward and outward interactions. This behavior implies that the energy of ejections was allocated to the force needed to lift the patch canopy or that the flow in the wake was returning to its ambient state by inflow from the high-speed free flow layer above.

\section{Limitations of the present study and future directions}

One possible reason for the substantial difference in the power spectral density results for M. spicatum (Fig. 6) may be the noise contamination of the signal. Brand et al. (2016) depicted how PSD values differ when using certain bins, due to different noise contributions connected to the SNR level. Although bins were chosen using the best mean SNR in the present study, the noise contribution was found to affect higher frequencies. An effect of noise was also visible in the increased contribution of longitudinal velocity fluctuations in the quadrant analysis of point downstream of M. spicatum (Fig. 7). On the other hand, the used SNR and correlation thresholds were the same as in field experiments conducted by Cassan et al. (2015) or Afzalimehr et al. (2017), and with the used filtering procedure, the obtained results were not below accepted requirements. Though, a caution in generalization of the presented interpretation is advised due to a scarcity of similar experiments.

Nikora et al. (2008) and Cornacchia et al. (2018) showed how dimensions of aquatic plants and their positions in the river channel determine their impact on the flow. The presented outcomes of two distinct patches showed how big influence on water mixing may have patch dimensions. However, without further downstream profiles and accurate plant density values it is impossible to determine, whether the M. spicatum canopy resembles one of the patches used in laboratory studies such as in Zong and Nepf (2012), where vortex street was generated. What is more, patches with enhanced horizontal flow deflection, i.e., which are denser and with lower submergence ratio, should produce greater velocity gradient at patch edge and therefore changing the sedimentation process, while wide patches, i.e., patch width $/ h>4$ produce vertical deflection (Ortiz et al. 2013). However, the results of the present study, were not sufficient enough to prove this relationship, but we do believe that additional field measurement of velocity profiles at the edges of the patches of different dimensions will provide valuable information about this interaction, which finally should help in building advanced hydrodynamics flow-biota models.

In the perspective of river ecology, the existence of a large patch promotes increased sedimentation in its wake (e.g., Cotton et al. 2006; Ortiz et al. 2013) and stimulates further growth downstream (Cornacchia et al. 2018). The question arises of whether impact on the flow and the sediment of wide patches is equal to the impact of more slender ones, assuming that the covered area of the patches is the same. Further case studies including plant growing in different configurations with a denser grid of velocity profiles, sediment traps and biomechanical tests of aquatic plants should provide relevant data to unify vegetated flow models and the impact of patch characteristics on river morphology.

\section{Summary}

Turbulent statistical analysis of the 3D velocity recorded with Vectrino Profilers in two distinct aquatic plant patches provided the following insights:

- Distinctive peaks in both, the turbulence intensity and turbulent kinetic energy downstream of M. spicatum, indicated the increased lateral mixing, which was also present downstream $M$. spicatum, but of a smaller magnitude.

- Comparing the TKE values in the downstream points closest to the bed, i.e., below $Z / H=0.2$, as in case of the second patch, a layer of the decreased TKE was observed, while at the same distance downstream of M. alterniflorum, i.e., at the profile 2 , the TKE was similar to the profile upstream.

- The power spectral density of the velocity fluctuation below the plant height showed the occurrence of a mixing layer downstream of $M$. spicatum and the energy downstream of $M$. alterniflorum dissipated faster in the closer profile.

- The bursting cycle downstream of both plants was disturbed, i.e., the ejections diminished and the number of sweeps, as well as inward and outward interactions increased.

These results are generally in line with the findings of similar investigations of flow around natural aquatic plants, 
especially in the case of M. spicatum. The smaller and slenderer patch of $M$. alterniflorum influenced the flow field less than did the second plant patch. The presented analysis showed that after thorough evaluation, filtering and despiking procedures, velocity recordings of a lower quality than those acquired in laboratory conditions can lead to meaningful results.

Acknowledgements This work was supported by the National Science Centre, Poland, Grant No. UMO-2014/13/D/ST10/01123 "Field experimental investigation of hydrodynamics of water flow-vegetation-sediment interactions at the scale of individual aquatic plants." The publication has been partially financed from the funds of the Leading National Research Centre (KNOW) received by the Centre for Polar Studies for the period 2014-2018.

\section{Compliance with ethical standards}

Conflict of interest On behalf of all authors, the corresponding author states that there is no conflict of interest.

Open Access This article is distributed under the terms of the Creative Commons Attribution 4.0 International License (http://creativeco mmons.org/licenses/by/4.0/), which permits unrestricted use, distribution, and reproduction in any medium, provided you give appropriate credit to the original author(s) and the source, provide a link to the Creative Commons license, and indicate if changes were made.

\section{References}

Aberle J, Järvelä J (2013) Flow resistance of emergent rigid and flexible floodplain vegetation. J Hydraul Res 51(1):33-45. https://doi. org/10.1080/00221686.2012.754795

Aberle J, Järvelä J (2015) Hydrodynamics of vegetated channels. In: Rowiński P, Radecki-Pawlik A (eds) Rivers: physical, fluvial and environmental processes. GeoPlanet: earth and planetary sciences. Springer, Cham, pp 519-541. https://doi.org/10.1007/978-3-31917719-9_21

Afzalimehr H, Barahimi M, Sui J (2017) Non-uniform flow over cobble bed with submerged vegetation strip. In Proceedings of the institution of civil engineers-water management. Thomas Telford Ltd, London, pp 1-16

Bialik RJ (2013) Numerical study of near-bed turbulence structures influence on the initiation of saltating grains movement. J Hydrol Hydromech 61(3):202-207. https://doi.org/10.2478/ johh-2013-0026

Biggs H, Nikora VN, Papadopoulos K, Vettori D, Gibbins C, Kucher M (2016) Flow-vegetation interactions: a field study of ranunculus penicillatus at the large patch scale. In: Webb JA, Costelloe JF, Casas-Mulet R, Lyon JP, Stewardson MJ (eds.) Proceedings of the 11th international symposium on ecohydraulics, Melbourne, Australia, 7-12 Feb 2016 Paper number 26153

Brand A, Noss C, Dinkiel C, Holzner M (2016) High-resolution measurements of turbulent flow close to the sediment-water interface using bistatic acoustic profiler. J Atmos Ocean Technol 33(4):769-788. https://doi.org/10.1175/JTECH-D-15-0152.1

Cameron SM, Nikora VI, Albayrak I, Miler O, Stewart M, Siniscalchi F (2013) Interactions between aquatic plants and turbulent flow: a field study using stereoscopic PIV. J Fluid Mech 732:345-372. https://doi.org/10.1017/jfm.2013.406
Cassan L, Belaud G, Baume JP, Dejean C, Moulin F (2015) Velocity profiles in a real vegetated channel. Environ Fluid Mech 15(6):1263-1279. https://doi.org/10.1007/s10652-015-9417-0

Chen Z, Jiang C, Nepf H (2013) Flow adjustment at the leading edge of a submerged aquatic canopy. Water Resour Res 49(9):5537-5551. https://doi.org/10.1002/wrcr.20403

Cornacchia L, Folkard A, Davies G, Grabowski RC, van de Koppel J, van der Wal D, Wharton G, Puijalon S, Bouma TJ (2018) Plants face the flow in $\mathrm{V}$ formation: a study of plant patch alignment in streams. Limnol Oceanogr. https://doi.org/10.1002/lno.11099

Cotton JA, Wharton G, Bass JAB, Heppell CM, Wotton RS (2006) The effects of seasonal changes to in-stream vegetation cover on patterns of flow and accumulation of sediment. Geomorphology 77(3-4):320-334. https://doi.org/10.1016/j.geomo rph.2006.01.010

Franca MJ, Santos BO, Antico F, Ferreira RML (2014) Quadrant analysis of coherent structures in open channel flows over mobile and immobile hydraulically rough beds. ERCOFTAC Bull 100:29-36

Ghisalberti M, Nepf H (2006) The structure of the shear layer in flows over rigid and flexible canopies. Environ Fluid Mech 6(3):277301. https://doi.org/10.1007/s10652-006-0002-4

Goring DG, Nikora VI (2002) Despiking acoustic Doppler velocimeter data. J Hydraul Eng 128(1):117-126. https://doi.org/10.1061/ (ASCE)0733-9429(2002)128:1(117)

Grass AJ (1971) Structural features of turbulent flow over smooth and rough boundaries. J Fluid Mech 50(2):233-255. https://doi. org/10.1017/S0022112071002556

Green JC (2005) Modelling flow resistance in vegetated streams: review and development of new theory. Hydrol Process 19(6):1245-1259. https://doi.org/10.1002/hyp.5564

Gurnell AM, Bertoldi W, Corenblit D (2012) Changing river channels: the roles of hydrological processes, plants and pioneer fluvial landforms in humid temperate, mixed load, gravel bed rivers. Earth Sci Rev 111(1-2):129-141. https://doi.org/10.1016/j.earsc irev.2011.11.005

Hu Z, Lei J, Liu C, Nepf H (2018) Wake structure and sediment deposition behind models of submerged vegetation with and without flexible leaves. Adv Water Resour 118:28-38. https://doi. org/10.1016/j.advwatres.2018.06.001

Hurther D, Lemmin UA (2001) Correction method for turbulence measurements with a 3D acoustic Doppler velocity profiler. J Atmos Ocean Technol 18(3):446-458. https://doi.org/10.1175/15200426(2001)018\%3c0446:ACMFTM\%3e2.0.CO;2

Kłosowski S, Kłosowski G (2007) Aquatic and marsh plants. MULTICO, Warsaw (in Polish)

Koca K, Noss C, Anlanger C, Brand A, Lorke A (2017) Performance of the Vectrino Profiler at the sediment-water interface. J Hydraul Res 55(4):573-581. https://doi.org/10.1080/00221 686.2016.1275049

Kolmogorov AN (1991) Dissipation of energy in the locally isotropic turbulence. Proc R Soc Lond A 434(1890):15-17. https://doi. org/10.1098/rspa.1991.0076

Kubrak E, Kubrak J, Kiczko A (2015) Experimental investigation of kinetic energy and momentum coefficients in regular channels with stiff and flexible elements simulating submerged vegetation. Acta Geophys 63:1405-1422. https://doi.org/10.1515/acgeo $-2015-0053$

Liu D, Liu X, Fu X, Wang G (2016) Quantification of the bed load effects on turbulent open-channel flows. J Geophys Res Earth 121(4):767-789. https://doi.org/10.1002/2015JF003723

Liu C, Hu Z, Lei J, Nepf H (2017) Vortex structure and sediment deposition in the wake behind a finite patch of model submerged vegetation. J Hydraul Eng 144(2):04017065. https://doi.org/10.1061/ (ASCE)HY.1943-7900.0001408

Łoboda AM, Karpiński M, Bialik RJ (2018a) On the relationship between aquatic plant stem characteristics and drag force: is 
modeling application possible? Water 10(5):540. https://doi. org/10.3390/w10050540

Łoboda AM, Przyborowski Ł, Karpiński M, Bialik RJ, Nikora VI (2018b) Biomechanical properties of aquatic plants: the effect of test conditions. Limnol Oceanogr Methods 16(4):222-236. https ://doi.org/10.1002/lom3.10239

Luchik TS, Tiederman WG (1987) Timescale and structure of ejections and bursts in turbulent channel flows. J Fluid Mech 174:529-552

Naden P, Rameshwaran P, Mountford O, Robertson C (2006) The influence of macrophyte growth, typical of eutrophic conditions, on river flow velocities and turbulence production. Hydrol Process 20(18):3915-3938. https://doi.org/10.1002/hyp.6165

Nepf HM (2012a) Hydrodynamics of vegetated channels. J Hydraul Res 50(3):262-279. https://doi.org/10.1080/0221686.2012.69655 99

Nepf HM (2012b) Flow and transport in regions with aquatic vegetation. Annu Rev Fluid Mech 44:123-142. https://doi.org/10.1146/ annurev-fluid-120710-101048

Nezu I, Nakagawa H (1993) Turbulence in open-channel flows. IAHRMonograph, Balkema

Nikora V (2010) Hydrodynamics of aquatic ecosystems: an interface between ecology, biomechanics and environmental fluid mechanics. River Res Appl 26(4):367-384. https://doi.org/10.1002/ rra. 1291

Nikora V, Larned S, Nikora N, Debnath K, Cooper G, Reid M (2008) Hydraulic resistance due to aquatic vegetation in small streams: field study. J Hydraul Eng 134(9):1326-1332. https://doi. org/10.1061/(ASCE)0733-9429(2008)134:9(1326)

Nikora N, Nikora V, O’Donoghue T (2013) Velocity profiles in vegetated open-channel flows: combined effects of multiple mechanisms. J Hydraul Eng 139(10):1021-1032. https://doi. org/10.1061/(ASCE)HY.1943-7900.0000948

O'Hare MT (2015) Aquatic vegetation: a primer for hydrodynamic specialists. J Hydraul Res 53(6):687-698. https://doi. org/10.1080/00221686.2015.1090493

Ortiz AC, Ashton A, Nepf H (2013) Mean and turbulent velocity fields near rigid and flexible plants and the implications for deposition. J Geoph Res Earth 118(4):2585-2599. https://doi. org/10.1002/2013JF002858

Parsheh M, Sotiropoulos F, Porte-Agel F (2010) Estimation of power spectra of acoustic-Doppler velocimetry data contaminated with intermittent spikes. J Hydraul Eng ASCE 136(6):368-378. https ://doi.org/10.1061/(ASCE)HY.1943-7900.0000202

Poggi D, Porporato A, Ridolfi L, Albertson JD, Katul GG (2004) The effect of vegetation density on canopy sub-layer turbulence. Bound Layer Meteorol 111(3):565-587. https://doi.org/10.1023/ B:BOUN.0000016576.05621.73

Przyborowski Ł, Łoboda AM, Bialik RJ (2018a) Experimental investigations of interactions between sand wave movements, flow structure, and individual aquatic plants in natural rivers: a case study of Potamogeton Pectinatus L. Water 10(9):1166. https://doi. org/10.3390/w10091166

Przyborowski Ł, Łoboda AM, Karpiński M, Bialik RJ (2018b) Characteristics of flow around aquatic plants in natural conditions: experimental setup, challenges and difficulties. In: Kalinowska MB, Mrokowska MM, Rowiński PM (eds) Free surface flows and transport processes. GeoPlanet: earth and planetary sciences. Springer, Cham, pp 347-361. https://doi.org/10.1007/978-3-31970914-7_23

Rominger J, Nepf H (2011) Flow adjustment and interior flow associated with a rectangular porous obstruction. J Fluid Mech 680:636659. https://doi.org/10.1017/jfm.2011.199
Siniscalchi F, Nikora V (2013) Dynamic reconfiguration of aquatic plants and its interrelations with upstream turbulence and drag forces. J Hydraul Res 51(1):46-55. https://doi.org/10.1080/00221 686.2012.743486

Siniscalchi F, Nikora VI, Aberle J (2012) Plant patch hydrodynamics in streams: mean flow, turbulence, and drag forces. Water Resour Res. https://doi.org/10.1029/2011WR011050

Sukhodolov AN (2015) Field-based research in fluvial hydraulics: potential, paradigms and challenges. J Hydraul Res 53(1):1-19. https://doi.org/10.1080/00221686.2015.1012126

Sukhodolov AN, Sukhodolova TA (2012) Vegetated mixing layer around a finite-size patch of submerged plants: Part 2. Turbulence statistics and structures. Water Resour Res. https://doi. org/10.1029/2011WR011805

Sukhodolova TA, Sukhodolov AN (2012) Vegetated mixing layer around a finite-size patch of submerged plants: 1 . Theory and field experiments. Water Resour Res. https://doi.org/10.1029/2011W R011804

Termini D, Di Leonardo A (2017) Turbulence structure and implications in exchange processes in high-amplitude vegetated meanders: experimental investigation. Adv Water Resour. https://doi. org/10.1016/j.advwatres.2017.11.020

Thomas RE, Schindfessel L, McLelland SJ, Creëlle S, De Mulder T (2017) Bias in mean velocities and noise in variances and covariances measured using a multistatic acoustic profiler: the Nortek Vectrino Profiler. Meas Sci Technol. https://doi.org/10.1088/13616501/aa7273

Tymiński T, Kałuża T (2012) Investigation of Mechanical Properties and Flow Resistance of Flexible Riverbank Vegetation. Pol J Environ Stud 21(1):201-207

Västilä K, Järvelä J (2018) Characterizing natural riparian vegetation for modeling of flow and suspended sediment transport. J Soils Sediments 18(10):3114-3130. https://doi.org/10.1007/s1136 8-017-1776-3

Västilä K, Järvelä J, Koivusalo H (2015) Flow-vegetation-sediment interaction in a cohesive compound channel. J Hydraul Eng 142(1):04015034. https://doi.org/10.1061/(ASCE)HY.19437900.0001058

Voulgaris G, Trowbridge JH (1998) Evaluation of the acoustic Doppler velocimeter (ADV) for turbulence measurements. J Atmos Ocean Technol 15(1):272-289. https://doi.org/10.1175/15200426(1998)015\%3c0272:EOTADV\%3e2.0.CO;2

Wahl TL (2003) Discussion of 'Despiking acoustic Doppler velocimeter data' by Derek G. Goring and Vladimir I. Nikora. J Hydraul Eng 129(6):484-487. https://doi.org/10.1061/ (ASCE)0733-9429(2003)129:6(484)

Welch PD (1967) The use of fast Fourier transform for the estimation of power spectra: a method based on time averaging over short, modified periodograms. IEEE T Acoust Electr 15(2):70-73. https ://doi.org/10.1109/TAU.1967.1161901

Wilson SJ, Ricciardi A (2009) Epiphytic macroinvertebrate communities on Eurasian watermilfoil (Myriophyllum spicatum) and native milfoils Myriophyllum sibericum and Myriophyllum alterniflorum in eastern North America. Can J Fish Aquat Sci 66(1):18-30. https ://doi.org/10.1139/F08-187

Zong L, Nepf H (2012) Vortex development behind a finite porous obstruction in a channel. J Fluid Mech 691:368-391. https://doi. org/10.1017/jfm.2011.479 